\title{
Culture and Conflict Management
}

\section{Style of International Project Managers}

\author{
Umar K. Mohammed \\ Gareth RT White \\ Guru P. Prabhakar (Corresponding Author) \\ Bristol Business School, the University of the West of England \\ Coldharbour Lane, Bristol. BS16 1QY. United Kingdom \\ Tel: 0044-117-328-3461Ｅ-mail: guru.prabhakar@uwe.ac.uk
}

\begin{abstract}
The management of culture has become increasingly important to many organisations and business disciplines, particularly multicultural and international project management. Cultural differences often result in varying degrees of conflict and require careful consideration. This study surveys 116 Project Managers using the Thomas-Kilmann Conflict Mode Instrument to determine their approach toward managing conflict. Indian, French and UK Project Managers' conflict management style are correlated with Hofstede's description of their cultural characteristics. We find that significant links between the cultural dimensions of Individualism and Masculinity with the propensity for Project Managers to adopt a Competitive style of conflict management. We also find Uncertainty Avoidance correlates with a tendency for Project Managers to adopt an Avoiding approach to conflict management. Other relationships are found between Hofstede's cultural dimensions and conflict management styles in Project Managers but their meaning requires further study.
\end{abstract}

Keywords: Culture, Conflict, Project Managers

\section{Culture}

The term business culture has become increasingly used since its introduction in the 1980's and its importance and effect upon all manner of organizations has achieved considerable significance especially as those organizations have engaged in more international exploits (Pheng and Yuquan, 2000). While internationalisation of business provides opportunity in terms of economies of scale and growth for example, it also presents special managerial difficulties. Failing to handle the diversity and complexity of host cultures and their integration with existing or intended organisational culture can be catastrophic. Poor employee motivation, low staff retention, marketing ineffectiveness and loss of competitive advantage are the potential results. On the other hand, successful cultural management can foster innovative practices, organisational knowledge creation and become a potential source of competitive advantage (Hoecklin, 1996; Evans, Hau \& Scuh, 1991; Hofstede, 1985).

It is widely understood that 'culture' represents an 'average' of the group or nation that is under consideration and that individuals may differ from this norm (Trompenaars and Hampden-Turner, 1997). This not only means that any approach toward cultural management will by definition be a compromise, but that many different approaches may be required for the numerous working groups that have been identified as having particular cultures, such as national culture (Hofstede, 1991), founder culture (Schein, 1985), professional culture (Hofstede, 1991; Schein, 1985), and organizational and corporate culture (O'Reilly and Pfeffer, 2000; Schwartz and Davis, 1981). One of the most influential pieces of business-culture research is that of Hofstede (1984) upon the employees in the international offices of IBM, yet even this has been subject to significant criticism. McCoy (2003) among others (Akande, 2002; Tardif, 2002; Giddens, 2000; Norchi, 2000), summarise these criticisms; that any description of culture will be an average, the model proposed by Hofstede identifies five characteristics of culture but does not describe their interrelationships, the model does not explain whether the observed culture displays for example the 'IBM-ness' of India or the 'Indian-ness' of IBM, and that the study is now out of date for reasons including changes in gender equality in developed countries and the globalisation of skilled personnel which has tended to dilute national distinctiveness.

Despite these criticisms, Hofstede's work has proved to have value in determining or predicting cultural traits (Samarah and Mykytyn, 2002; Triandis, 1995; Bartlett and Ghoshal, 1989). For example, Hofstede hypothesized that Russian managers would be characterized by high power distance, high uncertainty avoidance, medium-range individualism, and low masculinity (Hofstede 2001). Bollinger (1994) tested Hofstede's hypothesis in studies of Russian managers and found support for these predictions. Elenkov (1998) in his comparative study found that US 
managers are more individualistic than their Russian counterparts and the managerial culture in the United States is also characterized by lower power distance and uncertainty avoidance than the Russian managerial culture.

\section{Conflict Management}

Capozzoli (1999, p28) recognized that conflict "lies in the minds of those who are in conflict" and is usually only seen when it manifests as discord. Despite the immediate connotation of conflict being a destructive or inhibitive force it can in fact be healthy for an organisation if managed constructively. It may bring to light previously unseen pressures or discontents, it promotes problems to be addressed and may improve individuals' understanding of the goals and motives of others (Rollag, 2005; Van Slyke, 1999; Capozzoli, 1999; Singh and Johnson, 1998; Klunk, 1997; Butler, 1973). Poor management however leads to the inevitable loss of team and organisational trust and bonds, and reduced motivation (Cloke and Goldsmith, 2000; Capazzoli, 1999). A multi-cultural team is exposed to many of the sources of conflict to an even greater degree than a mono-cultural team, because of the different value systems among its members. Thus the multi-cultural project manager must be capable of managing cultural conflict and be able to handle the conflicts effectively in order to improve the team's performance. Kezsbom (1992) identifies potential sources of conflict in a project including scheduling, managerial and administrative procedures, communication, goal definition, resource allocation, reward methods, personalities, cost, technical knowledge, politics, leadership style and presence of ambiguity. The cultural traits identified by Hofstede and others that are likely to contribute to each of these sources of conflict are listed although their relative significance is not known.

Much of the current conflict management research stems from the work of Blake and Mouton (Borisoff and Victor, 1989), who identified five main conflict management approaches, namely problem-solving, smoothing, forcing, withdrawal and sharing. Subsequent authors have built on this framework with subtle changes to terminologies such as the Thomas-Kilmann model which is based on five conflict management methods of competing, collaborating, compromising, avoiding and accommodating (Table 1). The survey is used to identify an individual's conflict management behaviour, but also to demonstrate that the individual can increase his/her effectiveness through deliberately choosing a mode in conflict situations (Kilmann, 2007). Thomas and Kilmann maintain that we are all able to use each of the five approaches to conflict management though we may naturally prefer one style above another. Furthermore, this preference may change depending upon the specific circumstances of an instance of conflict, or it may change in response to our own personal disposition at that particular time.

\section{Project Management and Culture}

According to Hoffer, George and Valacich (2002), it is important for a Project Manager to possess a diverse set of skills; management, leadership, technical, customer relationship, and conflict management. Project Managers must be able to use this suite of skills to build an environment in which the project not only achieves its immediate goals but also operates successfully in terms of meeting the subtle needs of its individual members. The importance of the cultural dimension of management is especially significant in the field of Project Management. Jessen (1992) for example, proposed that the requirements for Hofstede's cultural dimensions of power distance, individualism and uncertainty avoidance differ throughout the life cycle of a project, and therefore that cultural values have different effect during the phases of the project. Cultural patterns in project environments reflect cultural patterns in the wider society. Project Managers therefore operate within the entwined cultures of their society and of their organization and of their own specific project teams (Earley and Mosakowski, 2004).

Consequently, Project Managers must be sympathetic to the understated cultural requirements of each sector of their working environment. For example, the ability to communicate "bad news" and to manage performance are considered key skills for a successful Project Manager. Hofstede (2001) and others note that many cultures have subtle ways of operating (Yeung and Tung, 1996; Kohls, 1994). For instance providing feedback is commonly made in some collectivist cultures via a third party, and that failure to observe such practices may result in significant harm to the project environment (Slevin and Pinto, 2004; Aycan and Kanungo, 2000).

Previous work by Prabhakar (2006, 2005a b, 2004a b,) and Prabhakar \& Walker (2005, 2004a b c) based on 153 projects in total from 28 nations demonstrate that leadership in projects is a unique challenge as opposed to the leadership of operations. In projects the Project Manager has to continuously evaluate his or her style of leadership and change according to the requirements of the phase a project is in due to varied time pressures, deadlines etc. This ability to change from one style to another in projects has been termed switch leadership. Further studies by Walker \& Prabhakar $(2006,2005)$ across 25 nations studying 111 projects identified that leading multicultural teams is an enormous challenge where the choice of project manager and his or her team is crucial. Therefore in choosing the 'right' Project Manager and team they have identified four levels of maturity, viz.: ready, willing, able and optimal. Knowing a persons maturity level can facilitate the choice of a Project Manager and his or her team in multicultural projects. 


\section{Statement of Research Purpose}

Culture has been shown to be a significant factor in organisational management, particularly during the management of projects where multiple cultures are encountered simultaneously. Inability to successfully manage this conflict is likely to result in significant reduction in organisational performance and can inhibit the successful operation of project teams. This study aims to investigate the link between Project Managers' nationality and their preference to adopt a specific method for managing conflict.

The Thomas-Kilmann Conflict Mode Instrument is employed to ascertain the mode of conflict management that international Project Managers utilise. These results are correlated with Hofstede's values for each of the cultural indices; Power Distance, Individuality, Masculinity, Uncertainty Avoidance and Long-Term Orientation.

Hofstede suggests that the cultural attribute of Power Distance Index (PDI) relates to the way in which the society deals with uncertainty or ambiguity (Hofstede, 1983). In organisational or Project Management terms this may be interpreted as the degree to which authority is centralised. Individualism (IDV) is the relationship between an individual and his or her colleagues. Societies or cultures may be found where individuals exhibit high degrees of self-interest or concern for themselves and their immediate family, and these are termed Individual. Alternatively, Collective societies are those where an individual is concerned with the wellbeing of a wider group. In terms of Project Management a Collective culture may be desirable to ensure that the often multiple goals of the team are pursued above the goals of the individual. The importance that genders attach to social goals and personal goals is termed the Masculinity Index (MAS). Females are said to value relationship goals while males favour egotistic goals such as career and reward (Triandis, 1995). Masculine cultures tend to be assertive and highly competitive. Uncertainty Avoidance Index (UAI) measures anxiety about future changing conditions or events. This can manifest as the society's attempts to control uncertainties sometimes through the application of rules and protocol (Shackleton and Ali, 1990) whereas others tend to be more accepting of those future uncertainties. Hofstede later expanded his cultural dimensions to include Long-Term Orientation (LTO) that considers a culture's preference for perseverance; a comparatively short-term orientated culture would be one that valued tradition and social obligation.

We expect that the cultural indices of Individualism and Masculinity to show some degree of correlation with a propensity to adopt a Competitor conflict management style. We also expect countries with a high Uncertainty Avoidance Index to correlate with the propensity of their Project Managers to adopt an Avoider style of conflict management.

\section{Method and Results}

A survey was conducted among 150 Project Managers in a multinational telecoms organisation. The survey tool was posted on the internet to minimise cost and time of distribution and the survey sample were directed to the survey via a hyperlink within a mass email. 116 online questionnaires were completed, giving a response rate of $77 \%$. Figure 1 shows the proportion and nationality of project managers in the survey.

To maximise validity of the analyses those nationalities that were represented by less than fifteen responses were not included in the analysis. This study therefore focuses on the cultural characteristics and conflict management styles of Project Managers in France (15\%, 17 responses), the UK (28\%, 34 responses) and India (18\%, 21 responses).

Table 2 depicts the average Thomas-Kilmann conflict management style values for each national grouping (represented as percentages) and the number of respondents in descending order. It shows that a high percentage of Project Managers in France, and to a lesser extent in the UK, adopt a Competitive style of conflict management $(17.86 \%$ and $32.14 \%$ respectively) whilst the propensity to take this approach in India is very low $(7.14 \%)$. The next significant factor is that there is a tendency for Indian Project Managers to adopt an Avoider style of conflict management (32.68\%) whereas in France and the UK this is less prevalent (18.38\% and 27\% respectively).

The Conflict Management Styles across the 116 respondents in Figure 2 indicate that there is no particular dominant style among the observed sample of project managers.

Correlation-coefficient was used to identify the correlations between the results and Hofstede's dimensions. Cohen (1988) has suggested small, medium and large interpretations for correlations in psychological research, shown at the top of Table 3, and these interpretations of analyses have been adopted in this study.

\section{Analysis and Discussion}

The correlation coefficients between Hofstede's cultural attributes and the Conflict Management Styles are reported in Table 3.

As seen from Table 3 the values of the correlations between Competing-IDV $(0.82,-0.21,0.75)$ are large for both France and UK and small but negative for India. France and UK are both identified by Hofstede as being highly 
Individual cultures where people are more concerned with their own well being than that of others. The correlation confirms a logical link between an individual's self-concern and their likelihood of adopting a Competitive style of conflict management. India, being less Individual than both France and UK displays a corresponding reduction in its Project Managers tendencies to behave in a Competing fashion.

Competing-MAS $(0.56,-0.03,0.94)$ shows a strong correlation for France and UK and small for India. Hofstede finds that the UK is most Masculine of the three countries, followed by India then France. Highly Masculine cultures may be expected to display more aggressive or assertive traits and therefore be likely to correlate highly with Competing styles of conflict management. As expected, the correlations between Competing and Masculinity mirror those of Competing and Individualism with both France and UK appearing Competitive.

Avoiding-PDI $(-0.29,0.57,0.93)$ are large for India and the UK and small but negative for France. Power Distance Index relates to the accepted inequality of power in a social system and Hofstede found that France and India displayed this to a higher degree than the UK. The strong correlations between these factors in both India and UK do not reflect the relative differences found by Hofstede and thus suggest that any link between an Avoiding conflict management style and PDI is not necessarily meaningful.

Avoiding-UAI $(0.52,0.55,0.46)$ are large for both France and India and medium for UK. Uncertainty Avoidance Index represents the tolerance of uncertainty or ambiguity. A culture with high UAI would be expected to enforce rules or procedures to minimize unstructured situations. It could be expected that any culture that avoids uncertainty would also avoid confrontation and therefore adopt an Avoiding strategy. Hofstede reports considerably higher tolerance in France than either UK or India. While these results do not reflect the scale of difference that Hofstede identified within this cultural dimension it is notable that propensity to adopt an Avoiding style is correlated across all three observed countries with the dimension of Uncertainty Avoidance.

\section{Conclusions}

This study finds significant links between Hofstede's cultural dimensions of Individualism and Masculinity with the propensity for Project Managers to adopt a Competitive style of conflict management. It also finds Uncertainty Avoidance correlates with a tendency for Project Managers to adopt an Avoiding approach to conflict management. Other relationships are found between Hofstede's cultural dimensions and conflict management styles in Project Managers but their meaning requires further study.

It is clear that cultural traits influence the approach of Project Managers toward conflict management and this is a new insight into the complexities of the management of multicultural projects. Project Managers need to be aware of the cultural attributes of their teams but also of the ways in which their actions are somewhat determined by their own cultural attributes.

There is some conflict around how the cultural tensions within project teams should be managed. Sujansky (2004) suggests a number ways for Project Managers to improve their ability to handle cultural issues, while White (1999) asserts that they must respect and support team diversity, and Evaristo (1993) suggests that Project Managers demonstrate inclusiveness by being receptive to alternative perceptions and thus encourage novel solutions to problems. Vereen (2004) however adopts a different perspective and highlights the importance of each individual in the project team to take responsibility for recognizing and appreciating others.

While this study illuminates the degree to which cultural attributes affect the likely approach that Project Managers may take in dealing with team conflict further research is needed to understand how Project Managers may moderate or change their attitude for the benefit of the project team.

This research has been undertaken in a single multinational telecoms company hence the sample may be more indicative of the multi-national business culture than of their national culture. Future studies may explore the link between conflict management style and cultural traits in other single culture and multi-culture working environments.

\section{References}

Akande W., (2002). The Drawbacks of Cultural Globalization. Yellow Times, Global Policy Forum Publications.

Aycan, Z., \& Kanungo, R.N. (2000). Impact of culture on human resource management practices: a ten-country comparison. Applied Psychology: An International review. 49 (1), 192-221.

Bartlett, C. A. \& Ghoshal S. (1989). Managing across borders: the transnational solution. Boston, MA: Harvard Business School Press.

Bollinger, D. (1994). The four cornerstones and three pillars in the "House of Russia" management system. Journal of Management Development. 13 (2), 49-54. 
Borisoff, D. \& Victor, D.A. (1989). Conflict Management: A Communication Skills Approach. Prentice Hall.

Butler, Arthur G Jr, (1973). Project Management: A Study in Organizational Conflict. Academy of Management Journal, 16 (1), 84-101.

Capozzoli, T. K. (1999). Conflict resolution: A key ingredient in successful teams. Journal for Quality and Supervision, 56 (12), 3-5.

Cloke, K. \& Goldsmith, J. (2000). Conflict resolution that reaps great rewards. The Journal for Quality and Participation. 23 (3), 27-30.

Cohen, J. (1988). Statistical power analysis for the behavioral sciences (2nd ed.). Hillsdale, NJ: Lawrence Earlbaum Associates.

Earley, P. C., \& Mosakowski, E. (2004). Cultural intelligence. Harvard Business review, 139-146.

Elenkov, D. (1998). Can American management concepts work in Russia? A cross-cultural comparative study. California Management Review. 40 (4), 133-156.

Evans,W.A., Hau, K.C. \& Scuh, D. (1991). A cross-cultural comparison of managerial styles, Asia Pacific. International Management Forum, 15 (3/4), 28-32.

Evaristo, R. (2003). The management of distributed projects across cultures. Journal of Global Information Management. 11 (4).

Giddens A., Halliday F., Kaldor M. \& Gary J. (2000). Globalisation: Good or Bad?, LSE Debate, London School of Economics, Global Dimensions.

Hoecklin, L. (1996). Managing Cultural Differences: Strategies of Competitive Advantage, Addison-Wesley, Wokingham.

Hoffer, J.A., George, J.F. \& Valacich J.S. (2002). Managing the information systems project: In Modern Systems Analysis \& Design, 59-92.

Hofstede, G. (1983). Cultural Dimensions for Project Management, Butterworth \& Co (Publishers) Ltd. 1 (1).

Hofstede, G.H. (1984). Cultural Dimensions in Management and Planning, Asia Pacific Journal of Management Studies, 1 (2), 81-99.

Hofstede, G.H. (1985). The Interaction between National and Organizational Value System. Journal of Management Studies, 22 (4), 347-357.

Hofstede, G. (1991). Cultures and Organizations: Software of the Mind: Intercultural Cooperation and its Importance for Survival, McGraw Hill, New York.

Hofstede, G. (2001). Culture's consequences: comparing values, behaviors, institutions, and organizations across nations. $2^{\text {nd }}$ ed. Thousand Oaks: Sage Publications.

Jessen, S.A. (1992). The Nature of Project Leadership. Scandinavian University Press, Norway.

Kezsbom, Deborah S. (1992). Re-opening Pandora's Box: sources of project conflict in the '90's, Industrial Engineering, 24 (5), 54-59.

Kilmann, R.H. (2007). Thomas-Kilmann Conflict Mode Instrument. [Online] Available: http://www.kilmann.com/conflict.html (October 20th, 2007)

Klunk, S.W. (1997). Conflict and the dynamic organization. Hospital Materiel Management Quarterly. 19 (2), 37-44.

Kohls, L. R. (1994). Developing intercultural awareness. Dallas SIL Library.

McCoy S. (2003). Integrating National Culture into Individual IS Adoption Research: The Need for Individual Level Measures. Proceedings of the 9th Americas Conference on Information Systems (AMCIS), 1004-1007.

Norchi C. (2000). The Global Divide, from Davos ..., Boston Globe, February 1st, 2000, Global Policy Forum Publications.

O'Reilly, Charles A., \& Pfeffer, Jeffrey, (2000). Cisco Systems: Acquiring and Retaining Talent in Hypercompetitive Markets. Human Resource Planning, 23 (3), 38-52.

Pheng L.S., \& Yuquan S. (2000). An Exploratory Study of Hofstede's Cross Cultural Dimensions in Construction Projects. Management Decision. 20 (1), 1-16.

Prabhakar, G.P. (2004a). A Switch will Induce a Better Pitch. Project Management Days, Vienna, Austria. 
Prabhakar, G.P. (2004b). Switch Leadership. Pre-IRNOP Doctoral Conference at Helsinki University of Technology, Helsinki, Finland

Prabhakar, G.P. (2005a). Switch Leadership in Projects. Project Management Journal, 36 (2), 53-60.

Prabhakar, G.P. (2005b). Switch Leadership in Projects. Project Management Institute's Global Congress, Toronto, Canada.

Prabhakar, G.P. (2006). The Impact of Transformational Leadership on Project Success:An Empirical Study Using Structural Equation Modeling across Twenty-Eight Nations. Project Management Institute's Biennial Research Conference, Montreal, Canada.

Prabhakar, G.P., and Walker, S.E. (2004a). Switch Leadership. Cahier de Recherche n ${ }^{\circ} 04-02$. Lille Graduate School of Management, France.

Prabhakar, G.P. \& Walker S.E. (2004b). A Switch in Time Saves Nine I. Project Management Institute's Biennial Research Conference, London, UK.

Prabhakar, G.P. \& Walker S.E. (2004c). A Switch in Time Saves Nine II. ESC Lille International Seminar cum workshop, Lille, France.

Prabhakar, G.P., and Walker, S.E. (2005). Intercultural Team Maturity: Unity in Diversity. Cahiers de Recherche. Lille Graduate School of Management, France.

Prabhakar, G.P., and Walker, S.E. (2006). Intercultural Team Maturity Model: Unity, Diversity, Capability. Project Perspectives, 70-73.

Rollag, K. (2005). Managing Conflict on Project Teams. Web-based interactive "toolkit" that focuses on the different conflict-handling styles students use to resolve conflict and gives advice on how to resolve conflict and tension on teams. [Online] Available: http://faculty.babson.edu/krollag/personal/resume.html (February 18th, 2008)

Samarah, I., Paul, S. \& Mykytyn P. (2002). Exploring the links between cultural diversity, the collaborative conflict management style, and performance of global virtual teams. Eighth Americas Conference on Information Systems, Southern Illinois University at Carbondale.

Schein, E. (1985). Organizational Culture and Leadership, San Francisco, CA: Jossey-Bass, 1985.

Shackleton, V.J., \& Ali, A.H. (1990). Work-related values of managers: a test of the Hofstede model, Journal of Cross-Cultural Psychology. 21 (1), 109-118.

Singh, Amarjit, \& Johnson, Holly M. (1998). Conflict Management Diagnosis at Project Management. Journal of Management in Engineering, 14 (4), 48.

Slevin, D. P., \& Pinto, J. (2004). An overview of behavioural issues in project management. In P. W. G. Morris and J. K. Pinto (Eds), The Wiley guide to managing projects. Hoboken, NJ: John Wiley \& Son.

Sujansky, Joanne G. (2004). The Five Biggest Traps to Avoid when Leading a Diverse Group. Occupational Hazards. 66 (8), 23.

Tardif J. (2002). The Hidden Dimensions of Globalization: What is at Stake Geoculturally. PlanetAgora, May 29th, 2002, Global Policy Forum Publications.

Triandis, H.C. (1995). Individualism and Collectivism, Westview, Boulder, CO.

Trompenaars F., \& Hampden-Turner C. (1997). Riding the Waves of Culture: Understanding Cultural Diversity in Business (Second Edition). Nicholas Brealey Publishing, London.

Van Slyke E.J. (1999). Resolve conflict, boost creativity. Human Resource Magazine, 44 (12), 132-137.

Vereen, V.S. (2004). Valuing Diversity: The key to successful relationship building. Public Relations Tactics, 11 (8), 17.

Walker, S.E. \& Prabhakar, G.P. (2006). Intercultural Team Maturity Model: Unity, Diversity, Capability. Project Perspectives, 28, 70-73.

Walker, S.E. \& Prabhakar, G.P (2005). Intercultural Team Maturity. IPMA World Congress, New Delhi, India.

White, R.D. (1999). Managing the Diverse Organization: The Imperative for a New Multicultural Paradigm. Public Administration \& Management 4(4). [Online] Available: http://www.pami j.com/99_4_4_white.html (September $\left.29^{\text {th }}, 2007\right)$

Yeung, I.Y.M., \& Tung, R.L. (1996). Achieving Business Success in Confucian Societies; The Importance of guanxi (connections). American Management Association. New York. 
Table 1. Thomas and Kilmann's Conflict Management Styles

\begin{tabular}{|c|l|}
\hline Competing & $\begin{array}{l}\text { Individuals pursue their own goals at the expense of others. } \\
\text { Authoritarian. }\end{array}$ \\
\hline Accomodating & $\begin{array}{l}\text { Individuals support others in the pursuit of their goals. } \\
\text { Sympathetic. }\end{array}$ \\
\hline Avoiding & $\begin{array}{l}\text { Individuals neglect their own goals and those of others. } \\
\text { Circumventive. }\end{array}$ \\
\hline Collaborating & $\begin{array}{l}\text { Individuals attempt to find ways for themselves and others to achieve their } \\
\text { goals. }\end{array}$ \\
\hline Compromising & \begin{tabular}{l} 
Individuals attempt to partially fulfill their own goals and those of others. \\
\hline
\end{tabular} \\
\hline
\end{tabular}

Table 2. Conflict Management Styles by Country

\begin{tabular}{|c|c|c|c|c|c|c|c|}
\hline Country & Responses & Competitor & Collaborator & Compromiser & Avoider & Accommodator & TOTAL \\
\hline United Kingdom & 34 & $17.86 \%$ & $20.64 \%$ & $19.64 \%$ & $27.00 \%$ & $14.86 \%$ & $100.00 \%$ \\
\hline India & 21 & $7.14 \%$ & $17.86 \%$ & $19.64 \%$ & $32.68 \%$ & $22.68 \%$ & $100.00 \%$ \\
\hline France & 17 & $32.14 \%$ & $17.86 \%$ & $21.41 \%$ & $18.38 \%$ & $10.21 \%$ & $100.00 \%$ \\
\hline South Africa & 11 & $22.22 \%$ & $14.81 \%$ & $18.52 \%$ & $18.52 \%$ & $25.93 \%$ & $100.00 \%$ \\
\hline Germany & 8 & $20.30 \%$ & $17.29 \%$ & $23.12 \%$ & $18.80 \%$ & $20.49 \%$ & $100.00 \%$ \\
\hline Holland & 7 & $23.57 \%$ & $16.43 \%$ & $21.07 \%$ & $19.29 \%$ & $19.64 \%$ & $100.00 \%$ \\
\hline Australia & 4 & $12.50 \%$ & $16.07 \%$ & $26.79 \%$ & $19.64 \%$ & $25.00 \%$ & $100.00 \%$ \\
\hline Nigeria & 3 & $20.00 \%$ & $19.64 \%$ & $24.64 \%$ & $20.71 \%$ & $15.01 \%$ & $100.00 \%$ \\
\hline Poland & 3 & $25.00 \%$ & $21.43 \%$ & $17.86 \%$ & $14.29 \%$ & $21.43 \%$ & $100.01 \%$ \\
\hline Pakistan & 2 & $14.29 \%$ & $7.14 \%$ & $28.57 \%$ & $25.00 \%$ & $25.00 \%$ & $100.00 \%$ \\
\hline Ghana & 2 & $20.71 \%$ & $15.01 \%$ & $20.00 \%$ & $24.64 \%$ & $19.64 \%$ & $100.00 \%$ \\
\hline New Zealand & 1 & $21.43 \%$ & $12.50 \%$ & $19.64 \%$ & $25.00 \%$ & $21.43 \%$ & $100.00 \%$ \\
\hline Sweden & 1 & $18.52 \%$ & $14.81 \%$ & $14.72 \%$ & $25.73 \%$ & $26.22 \%$ & $100.00 \%$ \\
\hline Russia & 1 & $25.00 \%$ & $17.86 \%$ & $17.86 \%$ & $19.64 \%$ & $19.64 \%$ & $100.00 \%$ \\
\hline Spain & 1 & $23.12 \%$ & $18.80 \%$ & $20.30 \%$ & $20.49 \%$ & $17.29 \%$ & $100.00 \%$ \\
\hline TOTAL AVERAGE & 116 & $20.25 \%$ & $16.54 \%$ & $20.92 \%$ & $21.99 \%$ & $20.30 \%$ & $100.00 \%$ \\
\hline
\end{tabular}


Table 3. Correlation Coefficients

\section{Correlation}

Small 0.1 to 0.29

Medium

Large

0.3 to 0.49

0.5 to 1.0

$\begin{array}{lccccc}\text { France } & \text { Competitor } & \text { Collaborator } & \text { Compromiser } & \text { Avoider } & \text { Accommodator } \\ \text { PDI } & -0.28 & -0.03 & -0.22 & -0.29 & -0.09 \\ \text { IDV } & 0.82 & -0.07 & 0.14 & 0.38 & -0.08 \\ \text { MAS } & 0.56 & 0.24 & -0.12 & 0.11 & -0.12 \\ \text { UAI } & 0.16 & 0.28 & 0.24 & 0.52 & -0.02 \\ \text { LTO } & \mathrm{x} & \mathrm{X} & \mathrm{x} & \mathrm{x} & \mathrm{x}\end{array}$

$\begin{array}{lccccc}\text { India } & \text { Competitor } & \text { Collaborator } & \text { Compromiser } & \text { Avoider } & \text { Accommodator } \\ \text { PDI } & 0.14 & 0.11 & -0.14 & 0.57 & 0.22 \\ \text { IDV } & -0.21 & 0.28 & -0.02 & 0.28 & -0.12 \\ \text { MAS } & -0.03 & 0.11 & -0.02 & -0.9 & -0.19 \\ \text { UAI } & 0.17 & 0.27 & 0.18 & 0.55 & -0.21 \\ \text { LTO } & 0.12 & 0.46 & 0.12 & -0.07 & 0.91\end{array}$

$\begin{array}{lccccc}\text { UK } & \text { Competitor } & \text { Collaborator } & \text { Compromiser } & \text { Avoider } & \text { Accommodator } \\ \text { PDI } & -0.12 & 0.28 & -0.02 & 0.93 & 0.32 \\ \text { IDV } & 0.75 & -0.21 & -0.11 & -0.01 & -0.16 \\ \text { MAS } & 0.94 & 0.04 & 0.16 & -0.8 & -0.03 \\ \text { UAI } & 0.14 & 0.21 & 0.21 & 0.46 & -0.15 \\ \text { LTO } & -0.7 & 0.32 & 0.02 & -0.14 & 0.12\end{array}$




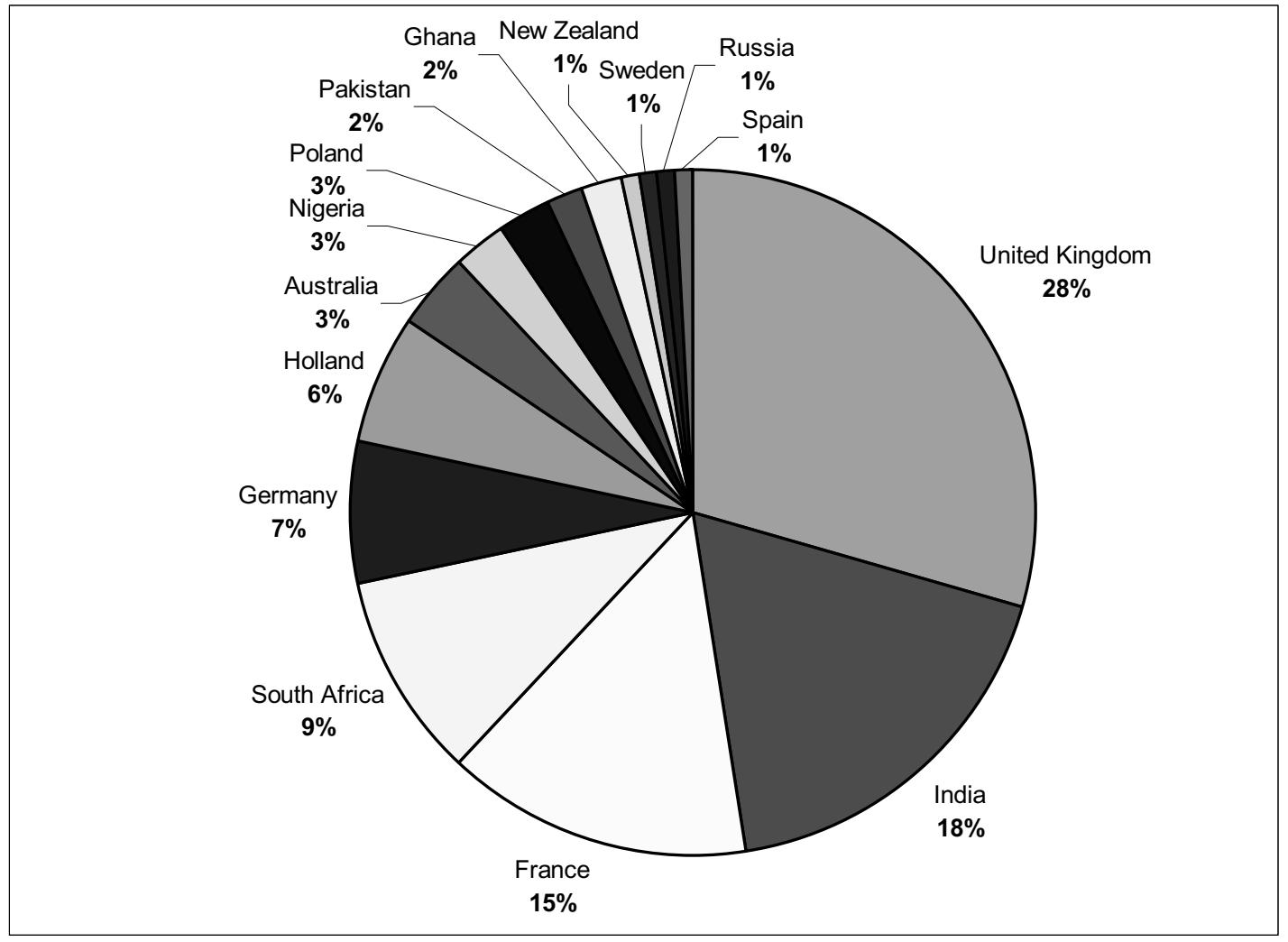

Figure 1. Survey Sample

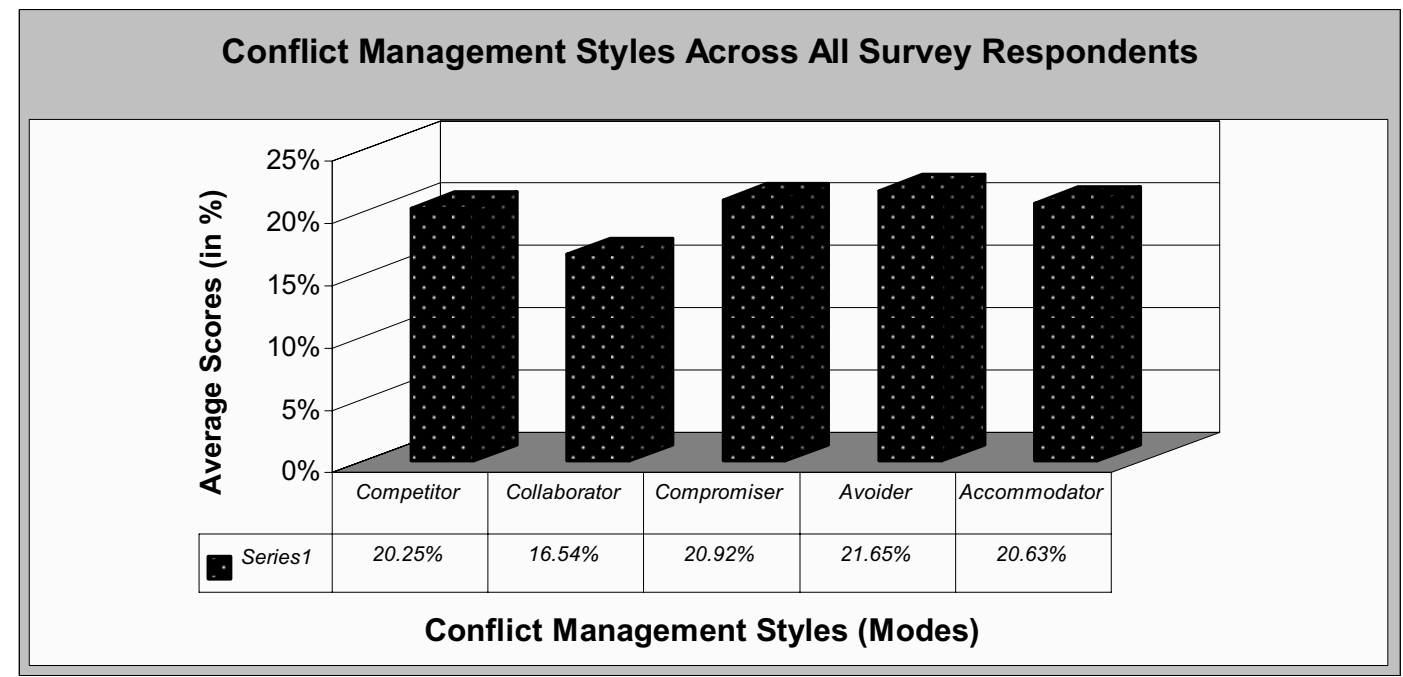

Figure 2. Average Conflict Management Styles across Survey Respondents 